\title{
The Society for Environmental Geochemistry and Health (SEGH): building for the future
}

\author{
Michael J. Watts - Taicheng An • Ariadne Argyraki • Emmanuel Arhin • \\ Anthea Brown - Mark Button · Jane A. Entwistle - Robert Finkelman • \\ Gillian Gibson - Olivier S. Humphrey $\cdot$ Xia Huo • Andrew S. Hursthouse • \\ A. Paula Marinho-Reis - Kakoma Maseka - Daniel R. S. Middleton • \\ Ofelia Morton-Bermea - Ahad Nazarpour • Akinade Shadrach Olatunji • \\ Odipo Osano - Sanja Potgieter-Vermaak - Sherestha Saini - Alex Stewart · \\ Moataz Tarek · Keith Torrance · Ming Hung Wong • Kosei E. Yamaguchi • \\ Chaosheng Zhang $\cdot$ Munir Zia
}

Published online: 2 August 2019

(C) Springer Nature B.V. 2019

The challenges of sustainable development are ever more pressing, and the skills, interests and capabilities of the SEGH member are well-placed to continue to make more meaningful contributions to the environment, society and well-being. We reflect on the historical development of the society, its response to

M. J. Watts $(\varangle) \cdot$ O. S. Humphrey

Inorganic Geochemistry, British Geological Survey,

Nottingham, UK

e-mail: mwatts@bgs.ac.uk

O. S. Humphrey

e-mail: bgsvisoli@bgs.ac.uk

T. An

School of Environmental Science and Engineering, Institute of Environmental Health and Pollution Control, Guangdong University of Technology, Guangzhou, China e-mail: antc99@163.com
A. Argyraki
Department of Geology and Geoenvironment, National and Kapodistrian University of Athens, Athens, Greece
e-mail: argyraki@geol.uoa.gr
E. Arhin
Department of Earth Science, Faculty of Earth and Environmental Sciences, University for Development Studies, Tamale, Ghana
e-mail: lordarhin@gmail.com

the dynamic international research landscape and the great opportunities ahead. In 2018, SEGH implemented a new board structure after 2-3 years of consultation, with approval of a new constitution and a new strategy across the large number of international board members. While regions were represented by

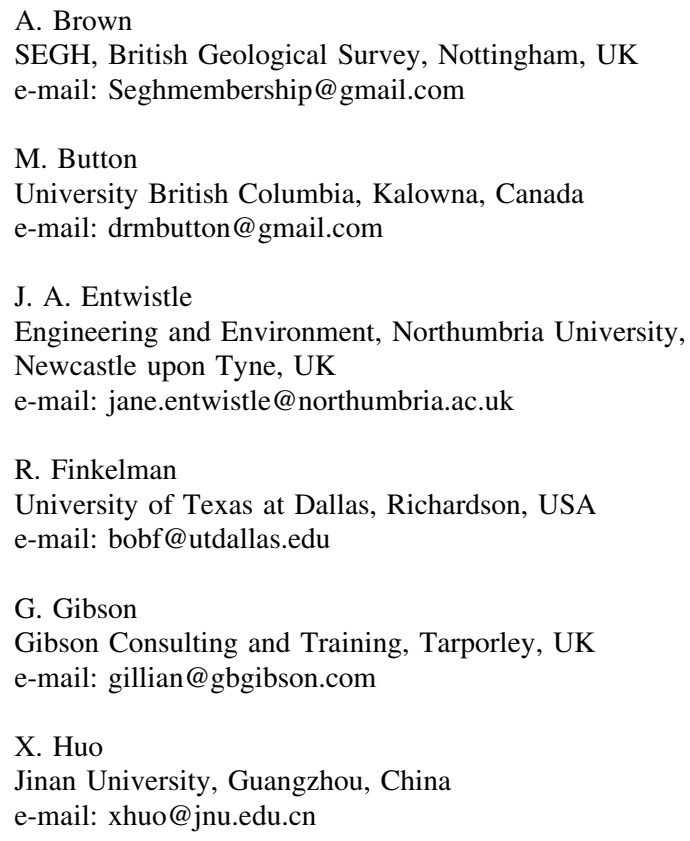


sections in Europe, Asia/Pacific and the USA, the structure required renewal in order to be more representative of the distribution of members and website traffic that had evolved in preceding years. In addition, the society wanted to improve its position for future growth opportunities across rapidly developing regions.

SEGH has been a welcoming society for early career researchers (ECRs) over the years, providing a supportive and encouraging atmosphere at conferences. However, a formal structure was required to continue to engage and support ECRs as they become established in their careers. In addition, retention and recognition of experienced scientists and practitioners were required for past and ongoing contributions to the long-standing success of SEGH since the initial formation in the early 1970s. The Society for Environmental Geochemistry and Health (SEGH) was first established in the USA to provide a forum for experts to work together in understanding the interaction between the geochemical environment and the health of plants, animals and humans. Wixson and Davies (2019) recently provided an account of the society's formation.

We offer this account of current initiatives and future aspirations to enhance the value that this society can offer to the SEGH community and beyond.

\footnotetext{
A. S. Hursthouse

University of the West of Scotland, Blantyre, UK

e-mail: andrew.hursthouse@uws.ac.uk
}

A. P. Marinho-Reis

Departamento de Ciências da Terra, Escola de Ciências, Universidade do Minho, Campus de Gualtarl, Braga,

Portugal

e-mail: pmarinho@dct.uminho.pt

K. Maseka

Copperbelt University, Kitwe, Zambia

e-mail:kkmaseka@gmail.com

\section{R. S. Middleton}

International Agency for Research Cancer, WHO, Lyon, France

e-mail: middletond@fellows.iarc.fr

O. Morton-Bermea

Instituto ed Geofísica, Universidad Nacional Autónoma de México, Mexico City, Mexico

e-mail: omorton@geofisica.unam.mx

\section{Evolution of SEGH}

The new international board structure of SEGH was formalised in 2018 so that there are now four representatives from each of the European, Americas, Asia/Pacific sections, with an additional African section established at the SEGH 2018 34th International Conference in Victoria Falls, Livingstone, Zambia (Watts et al. 2018). There is scope to co-opt and elect more board members in order to cover wider geographic and multidisciplinary aspects as a way of reinforcing the aspirational nature of SEGH.

Elected board members in 2018 came from the UK, Portugal and Greece for Europe; Kenya, Nigeria and Zambia for Africa; China, Japan and Pakistan for Asia/ Pacific and the USA and Mexico for the Americas. Coopted members enthusiastic to undertake new initiatives for growth in new regions/countries include Canada, Egypt, Ghana, Iran and Panama, with discussions progressing elsewhere.

In 2018, the first group of 22 ECRs (early career researchers) was established at the SEGH 2018 conference with initial plans to develop a programme of mentorship, training activities and interaction over a three-year period. ECR members were connected with appropriate SEGH 'experienced' and relevant members as mentors. This grouping is open to new ECRs as we evolve the programme and balance the

A. Nazarpour

Islamic Azad University of Ahvaz, Ahvaz, Iran

e-mail: ahad.nazarpour@gmail.com
A. S. Olatunji
Department of Geology, University of Ibadan, Ibadan, Nigeria
e-mail: as.olatunji@ui.edu.ng;
akinadeshadrach@yahoo.com
O. Osano
Department of Environmental Biology and Health, School of Environmental Studies, University of Eldoret, Eldoret, Kenya
e-mail: odipoosano@gmail.com
S. Potgieter-Vermaak
Manchester Metropolitan University, Manchester, UK
e-mail: s.potgieter@mmu.ac.uk
S. Saini
SpringerNature, New York, USA
e-mail: sherestha.saini@springernature.com 
demographics. The ECRs have been encouraged to establish a community to improve communication through social media and become involved in the peer review process for Environmental Geochemistry and Health (EGAH). The ECRs as a group are ideal for generating and testing new ideas and identifying trends to develop SEGH and potentially grow as individuals for succession management of the international board.

In 2019, SEGH launched a new Fellowship status for SEGH (FSEGH) encompassing senior researchers who have been engaged with SEGH for a number of years and maintained their membership., as well as demonstrating that they have worked hard in the EG\&H field, and supported the society in a variety of ways. The ECR group will have an opportunity to progress through to FSEGH via nomination from SEGH members, as will senior members with continuous scientific engagement and support of SEGH.

\section{Environmental Geochemistry and Health (EGAH) journal}

Environmental Geochemistry and Health is the official journal of SEGH published by Springer Nature, to which all members can subscribe and access the backcatalogue online via www.segh.net. The journal has been refreshing and updating the list of coordinating editors who are essential to the peer review process for articles submitted to EGAH. Candidates for this role who can commit to supporting the peer review process are welcome, particularly where SEGH can improve geographic diversity and coverage for emerging trends

\footnotetext{
A. Stewart

University of Exeter, Exeter, UK

e-mail: dragonsteeth@doctors.org.uk

M. Tarek

Geology Department, Faculty of Science, Arish

University, Arish, Egypt

e-mail: Moataz.tarek.m8@gmail.com

K. Torrance

University of Strathclyde, Glasgow, UK

e-mail: keith.w.torrance@strath.ac.uk

M. H. Wong

Southern University of Science and Technology,

Shenzhen, China

e-mail: Wongmh@sustech.edu.cn
}

across multidisciplinary themes and reinforce the involvement of health practitioners (clinical and public health)/epidemiologists. The journal has experienced continued and solid progress, particularly in recent years, with the impact factor progressing steadily (2018: 3.252) and the number of papers submitted increased from $400+$ in 2016 to $600+$ in 2018 , with a $40 \%$ acceptance rate.

\section{Future challenges}

Various challenges have resulted in a reduced membership in the USA in recent years, (which had been the cornerstone of the society for much of its history) although SEGH is not alone among societies in this experience. Growth in rapidly developing regions has balanced overall SEGH membership numbers. Greater geographical diversity across the Americas is required to ensure management succession, and efforts are ongoing to develop hubs to regrow membership in the Americas.

The peaks and troughs in membership in Asia/ Pacific, largely reflected by the well-attended SEGH international conferences in China, are both an opportunity and challenge to manage the membership and require imaginative solutions to retain and stabilise memberships between conferences. Nevertheless, core members from Asia are regular attendees at annual conferences as the conferences rotate between the regions.

An increase in African membership following on from the 34th International Conference at Victoria Falls-Zambia shows promise for continued

\author{
K. E. Yamaguchi \\ Toho University, Funabashi, Japan \\ e-mail: kosei@chem.sci.toho-u.ac.jp \\ K. E. Yamaguchi \\ NASA Astrobiology Institute, Mountain View, USA \\ C. Zhang \\ National University of Ireland, Galway, Ireland \\ e-mail: chaosheng.zhang@nuigalway.ie \\ M. Zia \\ Fauji Fertiliser Company Ltd, Rawalpindi, Pakistan \\ e-mail: munirzia@gmail.com
}


engagement with the African science community. The African board members have provided an example to other regions for regular communications, in particular making use of current communication platforms (e.g. WhatsApp and Skype) which have attracted additional senior researchers to online discussions to develop new SEGH hubs in Africa.

\section{Future meetings and conferences}

Traditionally, annual international conferences have rotated between regions, with the exception of the USA. Often, members have drifted away during the 2-3 years cycles, unless smaller meetings or cohosted meetings with other societies were organised, which more commonly have occurred in Europe. The SEGH board is backing an initiative on a wider scale to engage with traditional sponsors of our international conferences to support smaller regional meetings on a more frequent basis. Other options may need to be considered such as the use of online webinars and web streaming of keynote presentations.

Recent and future conferences and meetings include Slovakia in 2015, Belgium and Ireland in 2016, China in 2017, Zambia in 2018 and Greece and UK in 2019. In the run up to the 50th anniversary of SEGH in 2021, we will increase from one to two international conferences a year to be hosted in Eldoret-Kenya and Nanjing-China in 2020, with strong proposals in place for Portugal and Mexico in 2021. Co-badged meetings will become an increasing feature to improve engagement with members, with plans in place for 2020 in the USA and Ireland. Future conferences and meetings will aim to grow interest to attract epidemiologists and health practitioners in both curative and preventive fields, building on growing topics within SEGH in nutrition and agricultural research, which are highly relevant to Environmental Geochemistry and Health.

\section{SEGH and the future}

SEGH is at a critical point in its history. The competition for memberships to societies is intense and grows with financial challenges remaining ever problematic for members. Remaining relevant to current and future trends in scientific development and policy decisions will initially be supported by the recent initiatives, such as the ECRs and new geographical hubs with a fresh ability to review and critique our current position.

The multidisciplinary nature and sense of community within SEGH is as highly relevant now as when it was formed in the early 1970s. SEGH remains an effective platform for members to exchange ideas within their own field of interest. This has been emphasised in the past by SEGH membership that as a forum provides a strong and supportive environment (Stewart et al. 2012), which the board has tried to successfully sustain and grow. Following consultations with members, SEGH is strengthening efforts to better connect the diverse community that is SEGH, to encourage new and practical solutions to Environmental Geochemistry and Health challenges via collaborations. For example, the expansion of SEGH membership into rapidly growing regions (e.g. Africa, South East Asia) will help SEGH to keep up with emerging research challenges. Such a move presents an exciting opportunity to increase international collaborations to tackle increasing environmental pressures from anthropogenic activities (Brown et al. 2019; Kaninga et al. 2019; Olatunji and Afolabi 2019; Rodgers et al. 2019; Stewart 2019) that have an impact on human and animal health (Middleton et al. 2019). SEGH presents a platform for emerging technologies to identify and measure environmental pathways for contaminants via exposure and hazard assessment, in addition to interests in nutrition through deficiency of essential nutrients and transfer pathways from soil-toplant and onward animal/human health investigations (Watts et al. 2019).

SEGH has strengthened initiatives in recent years to draw in epidemiologists/health professionals; increasing emphasis on emerging contaminants; the role of agriculture and fisheries in ecological health through to food security. As in the early years of the formation of SEGH (Wixson and Davies, 2019), SEGH has a role in connecting increasingly complex and interconnected multidisciplinary studies to better inform stakeholders and policy decision makers. 


\section{Summary of future aspirations}

- Improve engagement with epidemiologists and health practitioners (clinical and Public Health) to improve translation of research into policy.

- Achieve greater editorial balance of EGAH geographically and to strengthen the 'Health' component.

- Increase the presence of epidemiologists and health practitioners (clinical and Public Health) within the conference programmes.

- Continue to increase regional membership hubs to grow geographical diversity of membership.

- Grow the Early Career Researcher programme for succession management within SEGH and 'stay on trend' with latest research.

- Evolve relevancy of SEGH goals to include the United Nations Strategic Development Goals to reinforce relevance to policy impact.

- Increase the membership of business colleagues, in order to encourage research, which is applicable to real-life situations.

\section{References}

Brown, A. D., Yalala, B., Cukrowska, E., Godoi, R. H. M., \& Potgieter-Vermaak, S. (2019). A scoping study of component-specific toxicity of mercury in urban road dusts from three international locations. Environmental Geochemistry and Health. https://doi.org/10.1007/s10653019-00351-1.

Kaninga, B., Chishala, B. H., Maseka, K. K., Sakala, G. M., Lark, M. R., Tye, A., et al. (2019). Review: Mine tailings in an African tropical environment-Mechanisms for the bioavailability of heavy metals in soils. Environmental
Geochemistry and Health. https://doi.org/10.1007/s10653019-00326-2.

Middleton, D. R. S., McCormack, V. A., Watts, M. J., \& Schuz, J. (2019). Environmental geochemistry and cancer: A pertinent global health problem requiring interdisciplinary collaboration. Environmental Geochemistry and Health. https://doi.org/10.1007/s10653-019-00303-9.

Olatunji, A., \& Afolabi, O. O. (2019). Assessment of Pb contamination of soils, sediments and dusts of the City of Lagos, Nigeria. Environmental Geochemistry and Health. https://doi.org/10.1007/s10653-019-00330-6.

Rodgers, K., McLellan, I., Peshkur, T., Williams, R., Tonner, R., Knapp, C. W., et al. (2019). The legacy of industrial pollution in estuarine sediments: Spatial and temporal variability implications for ecosystem stress. Environmental Geochemistry and Health, 1, 2-3. https://doi.org/10.1007/ s10653-019-00316-4.

Stewart, A. G. (2019). Mining is bad for health. Environmental Geochemistry and Health. https://doi.org/10.1007/s10653019-00367-7.

Stewart, A. G., Worsley, A., Holden, V., \& Hursthouse, A. S. (2012). Evaluating the impact of interdisciplinary networking in Environmental Geochemistry and Health: Reviewing SEGH conferences and workshops. Environmental Geochemistry and Health, 34, 653-664.

Watts, M. J., Maseka, K. K., Sakala, G., Mutondo, M. (2018). SEGH 2018 Vic Falls: Geochemistry for sustainable development, July 17, 2018 http://www.segh.net/articles/ segh_2018_vic\%20Falls_geochemistry_for_sustainable_ development/ [Accessed June 19, 2019].

Watts, M. J., Middleton, D. R. S., Marriott, A. L., Humphrey, O. S., Hamilton, E. M., McCormack, V., et al. (2019). Iodine status in western Kenya: A community-based cross-sectional survey of urinary and drinking water iodine concentrations. Environmental Geochemistry and Health. https://doi.org/10.1007/s10653-019-00352-0.

Wixson, B., \& Davies, B. (2019). The Society for Environmental Geochemistry and Health (SEGH): A retrospect. Environmental Geochemistry and Health, 1, 2-3. https:// doi.org/10.1007/s10653-019-00262-1.

Publisher's Note Springer Nature remains neutral with regard to jurisdictional claims in published maps and institutional affiliations. 